\title{
Comparison of efficacy of extramedullary fixation devices and proximal femoral nail in the management of subtrochanteric fracture femur
}

\author{
Santosh Deshpande ${ }^{1}$, Shriniwas Yemul ${ }^{2, *}$ \\ ${ }^{1}$ Assistant Professor, ${ }^{2}$ Associate Professor, Dept. of Orthopaedics, Ashwini Rural Medical College, Hospital \& Research Centre, \\ Kumbhari, Solapur, Maharashtra, India \\ *Corresponding Author: \\ Email: shinuortho@yahoo.co.in
}

\begin{abstract}
Introduction: Hip is one of the important joint for locomotion in human beings. So fractures in and around hip joint are of great concern to treating surgeon and patient. We have made an attempt to evaluate these complex fractures and compared the efficacy of proximal femoral nail and extamedullary devices in treatment of subtrochanteric fracture femur.

Materials and Methods: After informed consent was given, all 56 consecutive patients with subtrochanteric fracture of femur were randomized into two treatment groups. One group of patients were treated with dy namic hip screw or Dy namic condylar screw (Group I) and other group received proximal femoral nail (Group II). All procedures were performed by staff surgeons with patient supine on a fracture table.

Result: The mean operative time in Group I (93.57 min) was significantly higher than in Group II ( 80 min) with a P value of < 0.01. Average blood loss in Group I (190.14ml) was 2.4 times higher than in Group II (78.35 ml) with a P value of 0.008 . There was no significant statistical difference between the two groups with regard to general complications.

Conclusion: We conclude that subtrochanteric fractures are difficult to understand and manage. We consider that the PFN is a good minimally invasive implant for unstable proximal femoral fractures when closed reduction is possible. In general, PFN afforded early return to phy sical activity, faster rehabilitation \& walking ability, lesser blood loss and comparable success rate.
\end{abstract}

Keywords: Extramedullary fixation, Proximal femoral nail, Subtrochanteric fracture femur, Dy namic condy lar screw.

\section{Introduction}

During the last 50 years, the treatment of subtrochanteric femur fractures has evolved with improved understanding of both fracture biology and biomechanics. Previously, nonsurgical treatment of these fractures was associated not only with significant shortening and malrotation but also with the morbidity and mortality of prolonged immobilization. Early techniques of surgical repair demonstrated unacceptably high rates of complications; however, the benefits of restoring the anatomy and encouraging early mobilization are recognized and have led to significant research and improvement in implants. Currently, the subtrochanteric fracture remains technically challenging, even to experienced fracture surgeons .

The difficult nature of treating this fracture stems in part from the fact that this injury pattern is anatomically distinct from other proximal femoral peritrochanteric fractures and also from the difficult features of femoral shaft fractures. As a result, it must be treated with specially designed implants that can withstand significant muscular forces for prolonged periods of healing. This fracture has significantly higher rates of malunion and nonunion than other femoral fracture.

Subtrochanteric fractures account for approximately $10-30 \%$ of all hip fractures, and they affect persons of all ages. ${ }^{1}$ Most frequently, these fractures are seen in 2 patient populations, namely older osteopenic patients after a low-energy fall and younger patients involved in high-energy trauma. ${ }^{2}$
Despite introduction of newer designs, better implant quality and improvement in techniques of fixation, fractures of upper third of femur have been an enigma and pose a challenge to the Orthopaedic surgeon. Search for ideal implant and ideal method of fixation is still on. There is no widely accepted criterion for evaluation of functional results of these fractures in Indian patients, where squatting and cross legged sitting should be given special consideration.

By keeping these aspects in mind, through this study, we have made an attempt to evaluate these complex fractures and compared the efficacy of proximal femoral nail and extamedullary devices in treatment of subtrochanteric fracture femur. A modified criterion for assessment of results, suited for needs of Indian patients devised from Harris Hip score (1969) was used to evaluate all patients in our series.

\section{Materials and Methods}

56 patients with subtrochnteric fractures of femur reporting at ARMCH \& RC, Kumbhari over period of two years, were treated with either dynamic Hip screw, dynamic condylar screw or proximal femoral nail. Patients followed up of less than 6 months were excluded from the study.

Selection of Cases: Non pathological closed traumatic subtrochanteric fracture of femur normal femoral anatomy which allowed osteosynthesis.

Skeletally mature patients.

Patients with $>6$ month follow up.

The relative contraindications to the selection were, skeletally immature patients, compound fracture, 
pathological fracture, pre-existing femoral deformity preventing screw osteosynthesis or intramedullary nailing, previous surgery on ipsilateral hip or femur, those unable to cooperate in the post-operative rehabilitation programme because of senility, psychosis or parkinsonism.

Patients with $<6$ month follow up.

After informed consent was given, all 56 consecutive patients with subtrochanteric fracture of femur were randomized into two treatment groups. One group of patients were treated with dynamic hip screw or dynamic condylar screw (Group I) and other group received proximal femoral nail (Group II). All procedures were performed by staff surgeons with patient supine on a fracture table.

Detailed clinical history and a thorough physical examination were done for each patient and details of patients name, age, address \& occupation was recorded in the proforma. Conventional roentgenogramsanteroposterior \& lateral view of the affected hip and femur was taken. All these patients were then subjected to surgery after initial work up.

Classification of Patients: To assess the pre injury status the patients were classified because mental alertness and pre injury activities affect the decision. The preoperative parameters that were recorded include the age and sex of the patients, side of fracture, medical history and anaesthesia risk. The fracture was classified according to Russel taylor classification. ${ }^{3}$

The estimated blood loss, operative time, average drain volume and intra operative complications were recorded. The data pertaining to the type of fixation which included the length of lag screw, length of barrel plate, number of cancellous screws, number of cortical screws, interfragmentry screw, bone grafting, nail length and diameter were recorded. To assess operative risk the patients were classified according to Harris Hip Score and Parker Palmer mobility to assess pre injury activity level.

\section{Operative Technique}

Proximal Femoral Nail: The operative technique for fixation with PFN was same as described by Simmermacher et al. ${ }^{4}$ Under anaesthesia - spinal or combined spinal and epidural, patient was placed supine on fracture table. Closed reduction of fracture was attempted. Close reduction in AP plane was achieved by applying longitudinal traction and maintained in $25^{\circ}-10^{\circ}$ valgus position and then affected limb was fixed to foot piece of fracture table. All patients were given $1.5 \mathrm{gm}$ ceftriaxone IV preoperatively.

The standard PFN (with a length of 240-mm) was implanted by using a $5 \mathrm{~cm}$ skin incision extended from the cranial part to the tip of greater trochanter. After penetrating the fascia and muscles, a $2.8 \mathrm{~K}$ wire or a curved awl was inserted at the tip of greater trochater under fluoroscopic control in both planes. The guide wire is then driven through the track made by the awl under image guidance and successively reamed by cannulated reamers of increasing diameter. The proximal part of femur shaft was reamed with a $15-\mathrm{mm}$ reamer. The nail was then introduced manually into the femoral shaft.

Using image intensifier control the first guide wire was placed in the femoral neck so that the screw should be introduced no further to a horizontal line through the tip of greater trochanter. The neck screw should be introduced afterwards. In AP view the guide wire traversed the femoral neck centrally with tip engaging sub-chondral bone of lower quadrant of femoral head. In the lateral view, the guide wire was placed either centrally or slightly posteriorly in both femoral head and neck.

Dynamic HIP Screw: Standard lateral approach was used to expose the proximal femur. Lateral cortex was opened with a $2 \mathrm{~mm}$ drill bit and guide pin was inserted in the centre of femoral head and was advanced in the subchondral bone. Length was measured by using a direct measuring device. The path was then triple reamed and tapped. Selected lag screw was then inserted with a guide shaft. The DHS plate was then slid on to the assembly. With an impact or the plate was seated on to the lateral femoral cortex. The plate was then fixed to the shaft with the help of $4.5 \mathrm{~mm}$ cortical screws. The fracture was then impacted by first releasing traction and then with the compression screw. A suction drain was put under the vastus lateralis and the incision was closed in layers.

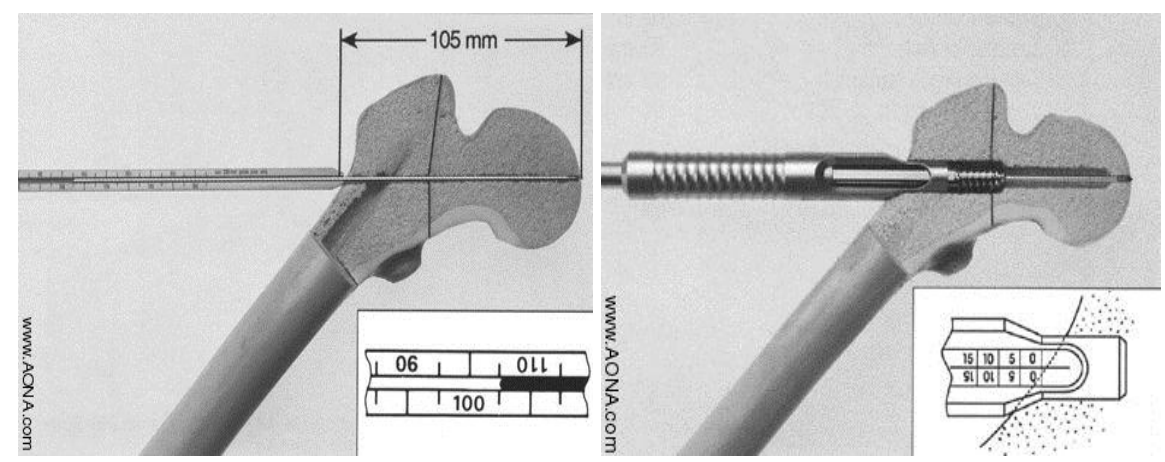

Image 1: 


\section{Image 2:}

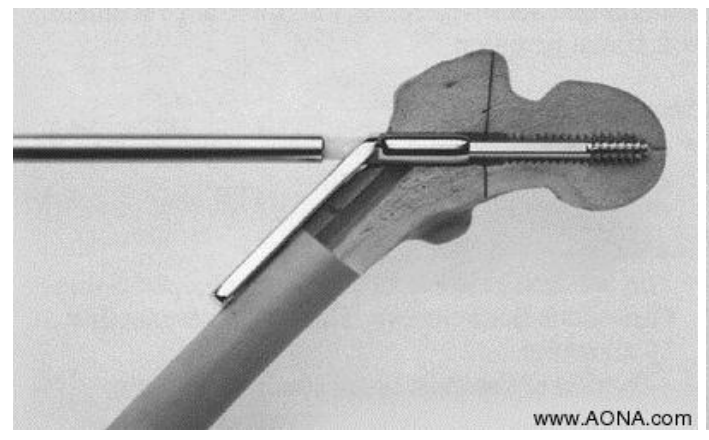

Dynamic Condylar Screw: Our operative technique for fixation with DCS was same as described by Baumgaertener et al. Under anaesthesia - spinal or combined spinal and epidural, patient was placed

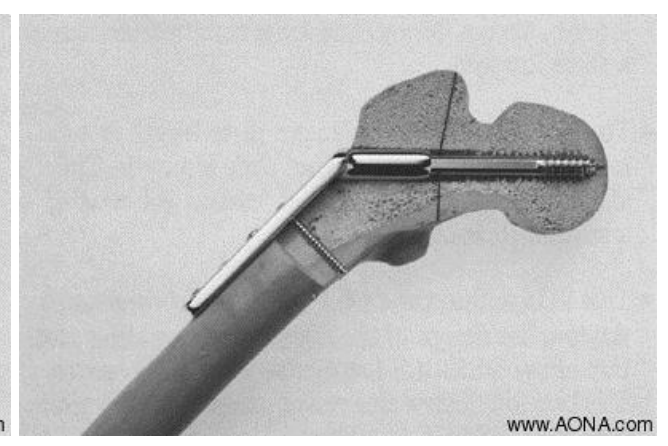

supine on fracture table. Closed reduction of fracture was attempted. Close reduction in AP plane was achieved by applying longitudinal traction and maintained in $25^{\circ}-10^{\circ}$ valgus position and then affected limb was fixed to foot piece of fracture table.

\section{Image 3:}
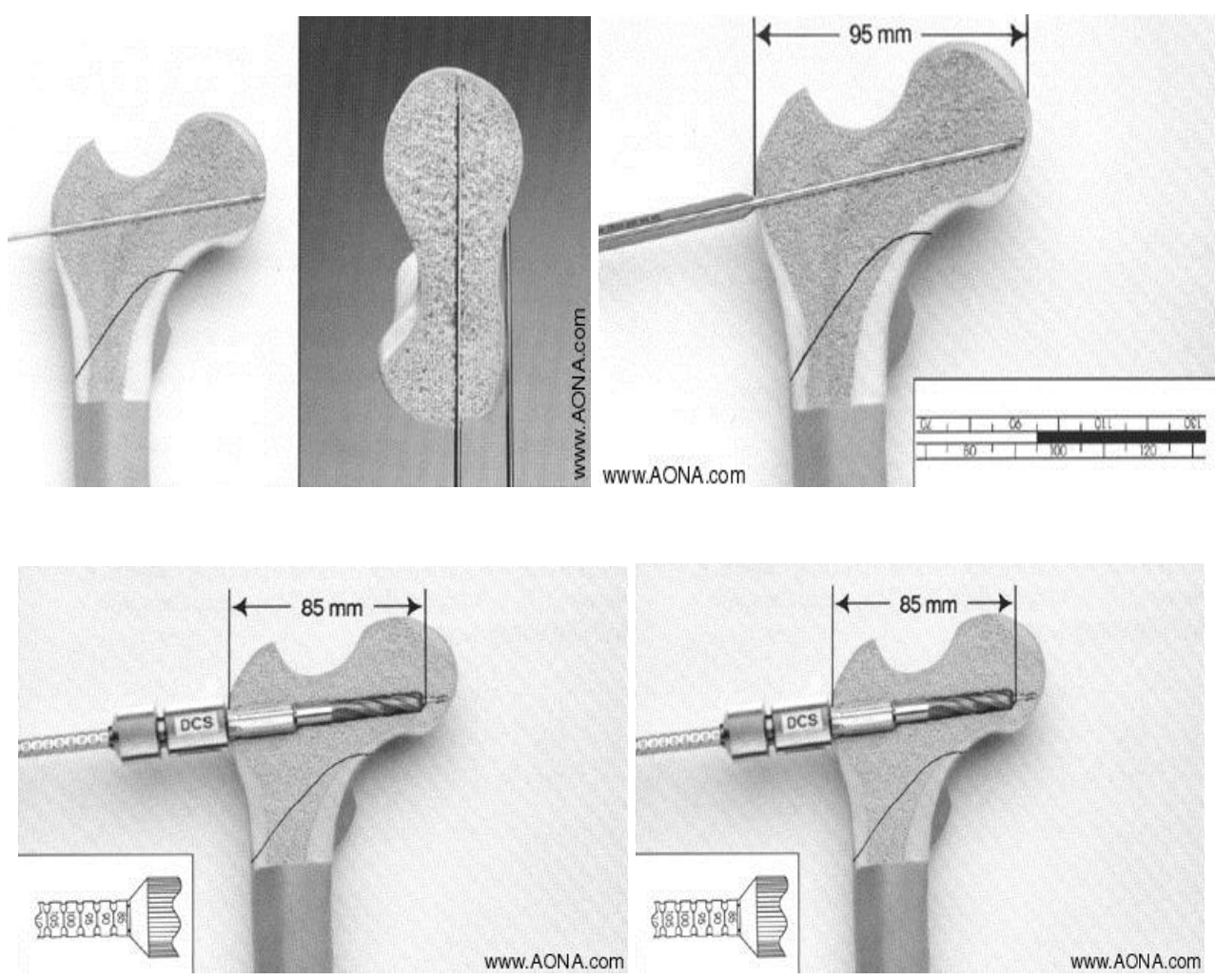

WWW.AONA.com

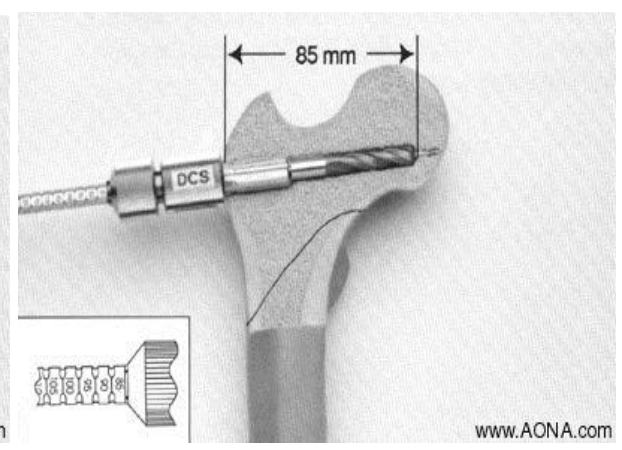

WWW.AONA.COM

Image 4:
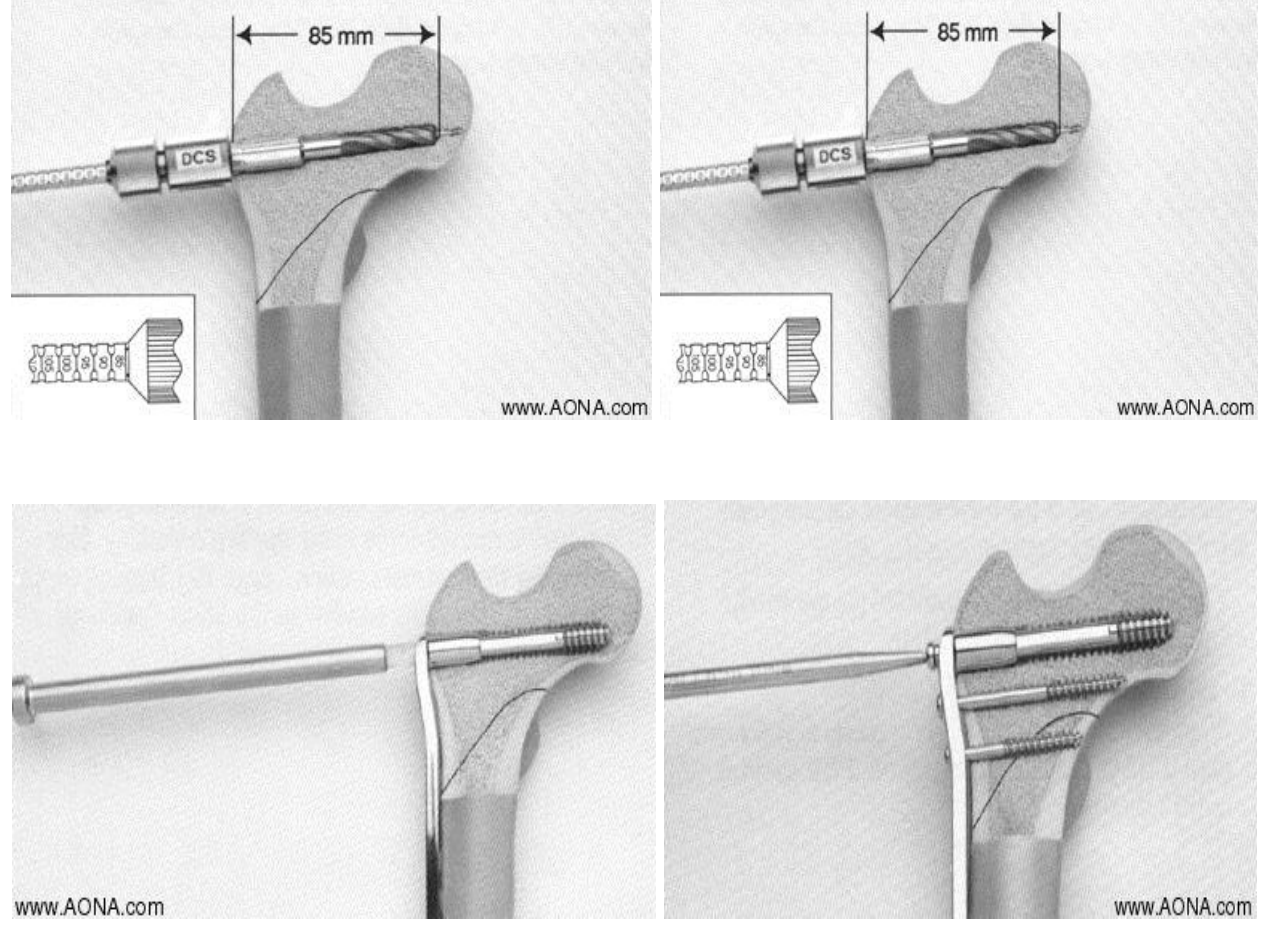

Image 5: 
The data pertaining to the type of fixation which included the number \& length of lag screw, length of proximal femoral nail, number of distal locking bolts, perceptive ease of reduction of fracture, tip apex distance, adequacy of reduction by criterion given by Baumgaertner et al., Quality of fixation was evaluated by checking the screw position inside the femoral head through Baumgaertner's 'tip apex distance' (TAP) and Parker's method.

\section{Classification of reduction (modified from Baumgaertner et al.) \\ I) Alignment \\ a. AP view: Normal cervico-diaphyseal angle or slight Valgus \\ b. Lateral view: Less than 20 deg of angulation}

II) Displacement of main fragments: More than $80 \%$ overlapping in both planes; less than $5 \mathrm{~mm}$ of shortening

Good: Both criteria met

Acceptable: Only one criterion

Poor: Neither criterion met

Post operative Protocol: Prophylactic antibiotics were continued postoperatively, parenterally three days and orally till tenth postoperative day. Wound inspection was done on 3rd operative day or earlier if there was gross soakage. Patients were mobilized out of bed on the third postoperative day. Walking with PWB was begun on $6^{\text {th }}$ postoperative day as tolerated. Stitches were removed on $15^{\text {th }}$ post operative day. Patient was discharged any day after 5th postoperative day when fit. The rehabilitation protocol was same for both the groups. Patients were examined clinically and radiographically on each visit. Patients were reviewed at 4 weekly intervals for follow up till union and final follow up.

All the patients were evaluated clinically and radiologically with respect to criteria modified from Harris hip Scoring System (1969) and criteria mobility score of Parker and Palmer, which uses a nine-point scale. Functional outcome was assessed by the postoperative mobility scores and functional indices were then compared to the pre-injury values.

Biomechanics of Proximal Femoral Nail: The proximal femoral nail is a load sharing device \& provides an efficient load transfer through the calcar because of its intramedullary fixation which is more medially located as compared to the lateral cortical fixation of the sliding hip screw.

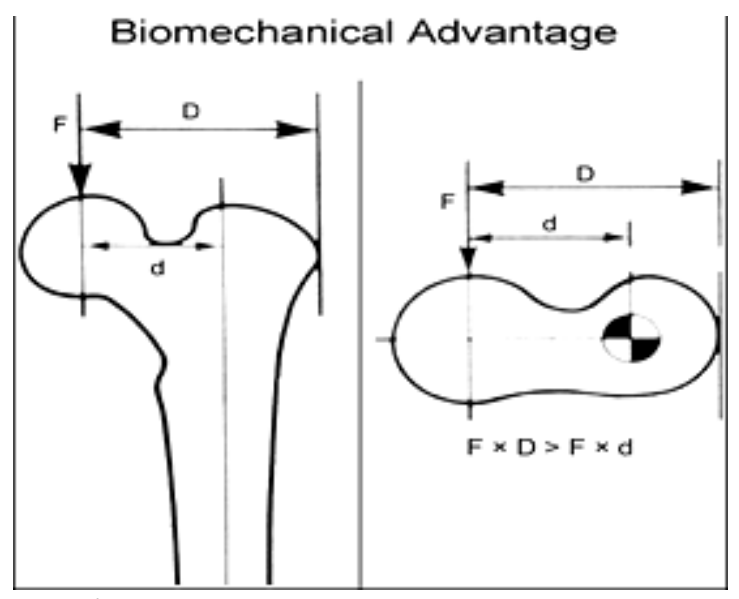

Image 6:

(The figure above shows that an intramedullary portion reduces the moment $(\mathrm{m})$ on the angle of the nail by reducing the distance (d) over which the bending occurs)

A shorter liver arm $(d<D)$ of the proximal femoral nail reduces the tensile strain due reduced bending moment and thus a reduced risk of failure. A comparative study to investigate the resistance to failure of femoral head screws used in DHS and PFN were done and PFN appeared to reduce the tendency to cut out in the osteoporotic bones and even hard bones the proximal femoral nail appeared to be stronger, the DHS showed a tendency to bend.

\section{Dynamic HIP Screw \& Dynamic Condylar Screw}

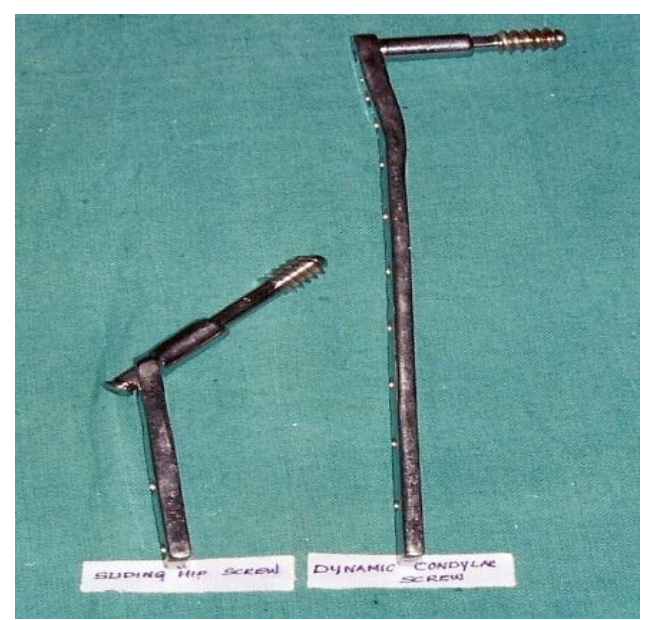

Image 7:

The Dynamic hip screw, a stainless steel implant produced from implant quality $316 \mathrm{~L}$ stainless steel which typically contains $62.5 \%$ iron, $17.6 \%$ chromium, 14.5\% nickel $2.8 \%$ molybdenum and minor alloy addition. A low carbon content is specified to ensure that material will remain free from susceptibility to intergranular corrosion. 
DHS Plates: These plates have a barrel length of 38 $\mathrm{mm}$ with two internal flats to guide the screw. The plate has staggered DCP holes and is fixed with $4.5 \mathrm{~mm}$ cortex screws.

The plates are available with $5,6,7,8,9,10,11,12,13,14,15$ and 16 holes lengths from $100 \mathrm{~mm}$ to $260 \mathrm{~mm}$.
Statistical Analysis: The student- t test was used to compare the two groups with regard to the mean age, mobility score, operative time, number of units of blood transfused and duration of hospitalization. Chi-Square analys is was performed to compare the two groups with regards to the difficulty of reduction and general complications. Differences were considered significant when the $\mathrm{p}$ value was $<0.05$.
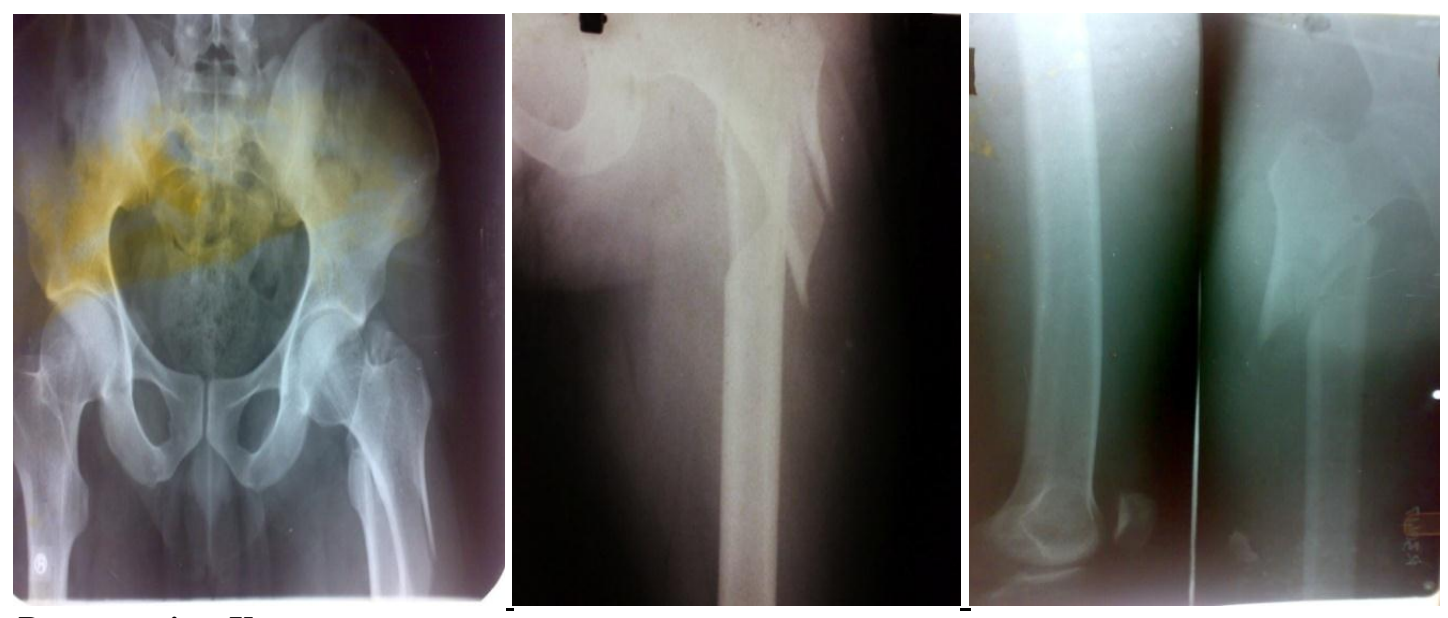

Fig. 1: Pre-operative X-rays
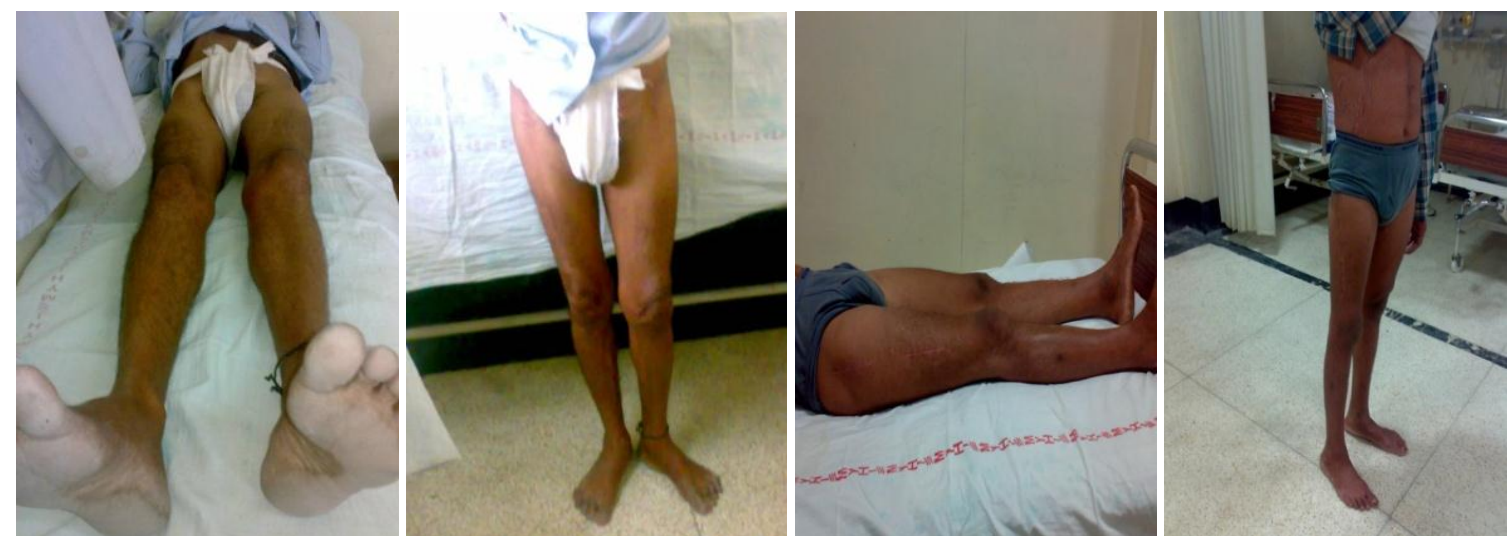

Fig. 2: Clinical pictures
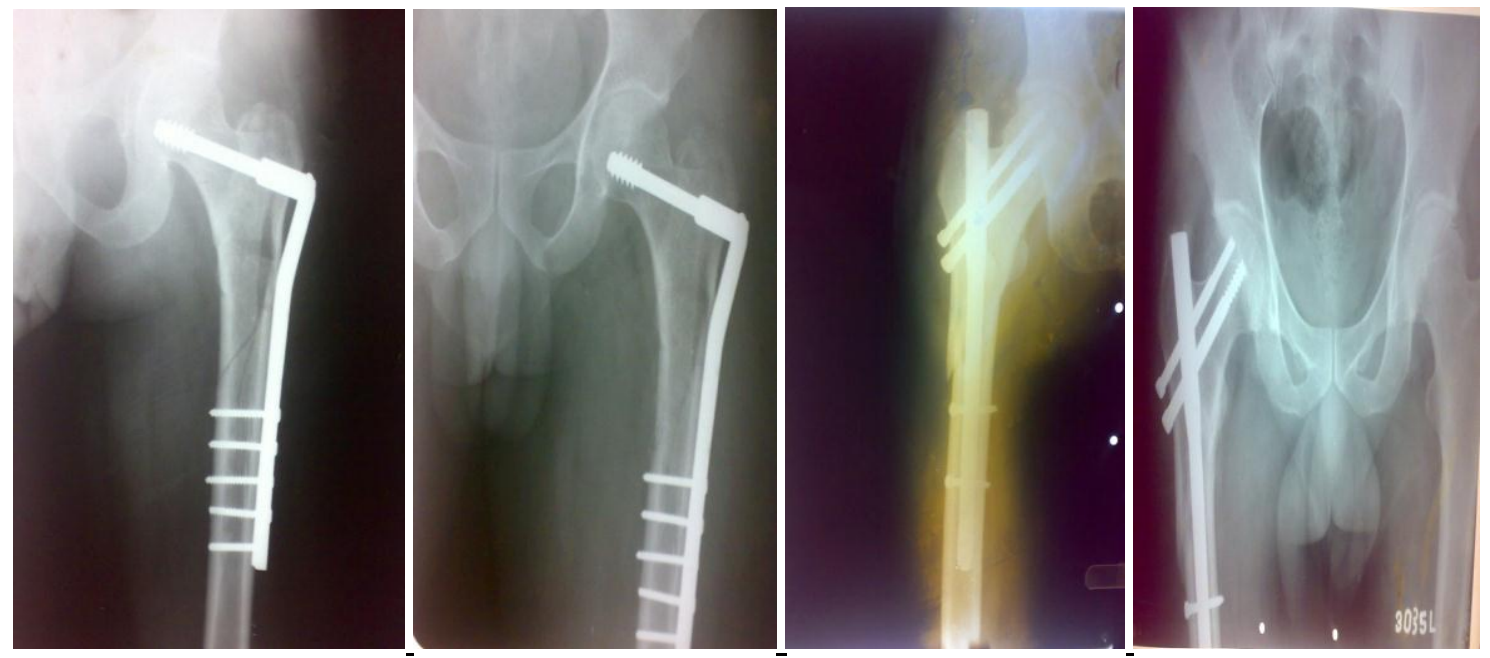

Fig. 3: Intra-operative pictures 


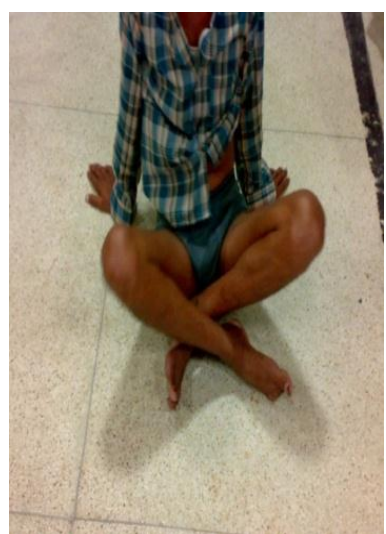

Fig 4: Results

\section{Results}

Table 1: Age distribution

\begin{tabular}{|l|c|c|}
\hline Age (in years) & Group I & Group II \\
\hline$<20$ & 2 & 2 \\
\hline $21-30$ & 4 & 5 \\
\hline $31-40$ & 8 & 7 \\
\hline $41-50$ & 6 & 8 \\
\hline $51-60$ & 6 & 4 \\
\hline $61-70$ & 2 & 1 \\
\hline $71-80$ & 1 & 0 \\
\hline
\end{tabular}

Maximum number of patients in this series were in the age group 30 to 50 years. No significant difference was observed between the two groups with regard to age $(\mathrm{P}=0.62)$.

Table 2: Sex distribution

\begin{tabular}{|l|c|c|}
\hline & Group I & Group II \\
\hline Male & 20 & 19 \\
\hline Female & 9 & 8 \\
\hline
\end{tabular}

Table 4: Operation related parameters

\begin{tabular}{|l|c|c|c|c|}
\hline \multirow{2}{*}{} & \multicolumn{2}{|l|}{ Group I } & Group II \\
\cline { 2 - 5 } & Frequency & Percentage & Frequency & Percentage \\
\hline Mode of trauma & & & & \\
\hline MVA high velocity & 14 & 48.3 & 8 & 29.6 \\
\hline MVA low velocity & 2 & 6.9 & 5 & 18.5 \\
\hline Slip and fall & 6 & 20.7 & 3 & 11.1 \\
\hline Fall from height & 7 & 24.1 & 10 & 37.0 \\
\hline Fall of heavy object & 0 & 0 & 1 & 3.7 \\
\hline Operative time (min) & & & & \\
\hline$<1 \mathrm{HR}$ & 02 & 6.9 & 3 & 11.1 \\
\hline $1-2 \mathrm{HR}$ & 22 & 75.9 & 24 & 88.9 \\
\hline$>2 \mathrm{HR}$ & 5 & 17.2 & 0 & 0.0 \\
\hline Blood loss & & & & \\
\hline$<50 \mathrm{ml}$ & 0 & 0.0 & 3 & 11.1 \\
\hline $50-100 \mathrm{ml}$ & 2 & 6.9 & 12 & 44.4 \\
\hline $100-150 \mathrm{ml}$ & 7 & 24.1 & 6 & 22.2 \\
\hline $150-200 \mathrm{ml}$ & 8 & 27.6 & 4 & 14.8 \\
\hline $200-250 \mathrm{ml}$ & 9 & 31.0 & 2 & 7.4 \\
\hline
\end{tabular}




\begin{tabular}{|l|c|c|c|c|}
\hline$>250 \mathrm{ml}$ & 3 & 10.3 & 0 & 0.0 \\
\hline Complications & & & & \\
\hline Wound infection & 3 & 10.3 & 1 & 3.7 \\
\hline $\begin{array}{l}\text { Implant related complication } \\
\text { (failure) }\end{array}$ & 2 & 6.9 & 0 & 0.0 \\
\hline Non-union & 2 & 6.9 & 1 & 3.7 \\
\hline Varus collapse (Malunion) & 3 & 10.3 & 0 & 0.0 \\
\hline Hospital Stay & & & & 0.0 \\
\hline$<1 \mathrm{WK}$ & 0 & 0.0 & 0 & 8 \\
\hline $1-2 \mathrm{WK}$ & 6 & 20.7 & 8.6 \\
\hline $2-3 \mathrm{WK}$ & 8 & 27.6 & 11 & 40.7 \\
\hline $3-4 \mathrm{WK}$ & 12 & 41.4 & 6 & 22.2 \\
\hline$>4 \mathrm{WK}$ & 3 & 10.3 & 2 & 7.4 \\
\hline Time to Union & & & & \\
\hline$<15 \mathrm{WK}$ & 2 & 6.9 & 5 & 18.5 \\
\hline $15-20 \mathrm{WK}$ & 10 & 34.5 & 17 & 59.3 \\
\hline $20-25 \mathrm{WK}$ & 17 & 58.6 & 6 & 22.2 \\
\hline
\end{tabular}

Mode of Trauma: In both the groups, MVA, high and low velocity followed by fall from height were the two most common modes of trauma and the difference was found to be insignificant statistically $(\mathrm{P}=0.22)$.

Operative Time $(\mathbf{m i n})$ : Most of the patients were operated within 2 hours. The average operating time in Group I was $93.57 \mathrm{~min}$ as compared to $80 \mathrm{~min}$ in Group II which was statistically significant $(\mathrm{P}<0.001)$.

Good or acceptable reduction was achieved in all patients.

Blood Loss: Average blood loss in Group I was 190.14 $\mathrm{ml}$ as compared to only $78.35 \mathrm{ml}$ in Group II ( $\mathrm{P}=0.008)$. Only 23\% patients in Group II required blood transfusions. This was significantly lower than Group II $(\mathrm{P}=0.008)$.

Complications: Wound related complications most common complications noted in Group I. One patient in Group II developed DVT. Three case of non-union was recorded which was subsequently treated with extramedullary fixation device supplemented with cancellous bone grafting at 8 months of follow-up. The patient showed good consolidation in 12 weeks.

Two patients in Group I developed implant related complication in the form of cut out of lag screw and loosening of plate at 16 weeks.

One patient in Group II developed deep infection which needed implant removal after union.

Three patients in Group I developed coxa vara (Neck shaft angle less than 125 degrees)

Hospital Stay: Average duration of hospital stay in Group I was 2.9 weeks as compared to 2.6 weeks in Group II. The comparison was significant with $\mathrm{P}$ value of 0.01 .

The average follow up duration in Group I was 34.86 weeks and in Group II was 32.6 weeks

Time to Union: The average union time in Group I was 20.57 weeks as compared to 18.25 weeks in Group II. The difference was significant $(\mathrm{P}=0.02)$ One case of non-union was recorded in Group II. This was probably due to placement of only one lag screw and less rigid fixation.

Table 5: HIP-thigh pain score

\begin{tabular}{|l|c|c|}
\hline Score & Group I & Group II \\
\hline 1 & 8 & 7 \\
\hline 2 & 10 & 10 \\
\hline 3 & 11 & 9 \\
\hline 4 & 0 & 1 \\
\hline
\end{tabular}

The average hip-thigh pain score in Group I was 2.28 as compared to 2.29 in Group II. No statistical difference was noted between the two groups $(\mathrm{P}=0.2)$

Table 6: Parker and palmer mobility scores

\begin{tabular}{|l|c|c|}
\hline Score & Group I & Group II \\
\hline 5 & 6 & 3 \\
\hline 6 & 5 & 3 \\
\hline 7 & 7 & 8 \\
\hline 8 & 6 & 7 \\
\hline 9 & 5 & 6 \\
\hline
\end{tabular}

The average Parker-Palmer mobility score in Group I was 7.21 as compared to 7.82 in Group II which was statistically significant $(\mathrm{P}=0.04)$

Table 7: Outcome

\begin{tabular}{|l|c|c|}
\hline Outcome & Group I & Group II \\
\hline Excellent & 8 & 9 \\
\hline Good & 14 & 15 \\
\hline Fair & 7 & 3 \\
\hline Poor & 0 & 0 \\
\hline
\end{tabular}

In Group I, there were $27.59 \%$ results were excellent, $48.28 \%$ were good and $24.14 \%$ results were fair as compared to Group II in which $33.33 \%$ results were excellent, $55.56 \%$ were good and $11.11 \%$ were fair. There were no poor results in both the groups. The 
final results in both the groups were comparable with a $P$ value of 0.1

\section{Discussion}

Age of patients varied from 15 to 75 years, youngest being 15 years and the oldest 76 years. $90 \%$ of the patients were below 60 years. Average age of patients in our study was 55 years, which is a decade lower than that in different reported series (Joseph Schatze, James P. Waddell- 1980 - 68 years ${ }^{5}$ ).

Males in the present study outnumbered females considerably in the ratio of 5:1. This finding in the present study is contrary to the published reports by Bruce WJ, Rizkallah SM, Kwon YM, Goldherg JA, Walsh WR F:M ratio $3: 1^{6}$

In the present study, high velocity trauma, due to road traffic accidents was responsible for majority of patients $(80 \%)$. Fall on ground as mode of trauma was seen in older individuals $(6 \%)$. Indirect injury due to fall on foot from height was mostly seen in younger age group patients $(10 \%)$. This is consistent with the view of Horn and Wang. ${ }^{7}$ In majority of the cases $(60 \%)$ right lower limb was involved.

Selected cases were classified radiologically based on Russell- Taylor classification. ${ }^{3}$ In this study, majority of the cases were of type IA, 16 of $50(32 \%)$ followed by type IIB 15 of 50 (30\%). Type IB (11 of 50 ) formed $22 \%$ and least was type IIA, 8 of $50(16 \%)$ We could not get any published series of the commonest type of fractures as per Russell-Taylor classification.

Mean operative blood loss and operative time were reported to be higher in extramedullary fixation implants in subtrochanteric fractures (Parker MJ, Handoll HA). ${ }^{8}$

In $90 \%$ of cases of extramedullary fixation implants, the average operative time were 120-150 minutes and mean blood loss was 400-600 ml. Mean operative time for intramedullary devices was 90-120 minutes with average blood loss of $3000400 \mathrm{ml}$.

Brien WW, Wis s DA, Becker V Jr., Lehman $\mathrm{T}^{9}$ in a series of 75 subtrochanteric fractures treated with extramedullary and intramedullary devices, found average operative time and blood loss to be 180-200 minutes, 500-600 $\mathrm{ml}$ and 150-180 minutes, 300-400 ml respectively. Duration of hospital stay was more or less equal. Average 1 week for both intramedullary and extramedullary devices.

Out of the 48 cases in our series, 27 cases achieved clinical and radiological union in 16-20 weeks. 16 cases united within 24 weeks. 2 cases united within 24-28 weeks. These cases were considered as delayed union. 3 cases of non-union were there in our study.

Fasaro FJ Jr., Olysav DJ, Stauffer ES in a series of subtrochanteric fractures treated surgically reported average healing time as 4.7 months. ${ }^{10}$

Dicicco JD, Jenkins M, Ostrum RF in their series of 16 cases of subtrochanteric fractures reported average time of union as 22.4 weeks (range 12.54 weeks ). ${ }^{11}$

Banquet A, Franciscoli L, Krenzi D, Lopez L (2000) evaluated the outcome of treatment of subtrochanteric fractures treated with intramedullary locking devices. The rate of union was $100 \%$ in this series with average union time of 4.3 months (range 3 to 6.5 months ).

Whattey JR, Garland DE, Whitecloud T, Whickstrom $\mathrm{J}$ in series of 23 subtrochanteric fractures treated with ASIF blade plate and DCS reported 17 primary union (0-6 months), 2 delayed union (6-12 months ). ${ }^{12}$

There were 3 cases of non-union (6\%), 1 case of bone deep infection (2\%) and 8 cases of malunion (15\%). Brien WW, Wiss DA, Becker V Jr., Lehman $\mathrm{T}^{9}$ in their study of 75 subtrochanteric fractures reported infection in 2 cases (2\%), malunion in 18 cases $(37 \%)$ and 4 cases of non-union (6\%).

Bergman GD, Winquist RA, Mayo KA, Hansen ST reported $5 \%$ non-union in their series of surgically treated 131 patients of subtrochanteric fractures. ${ }^{13}$

\section{Conclusion}

We conclude that subtrochanteric fractures are difficult to understand and manage. Road traffic accident is the commonest cause of these fractures and the productive group of society, young males, are mainly affected - may be an occupational hazard.

As early weight bearing may result in failure of implants, full weight bearing should only be allowed after sound union of fracture is confirmed radiologically. At present, we consider that the PFN is a good minimally invasive implant for unstable proximal femoral fractures when closed reduction is possible. In general, PFN afforded early return to physical activity, faster rehabilitation \& walking ability, lesser blood loss and comparable success rate.

\section{References}

1. Nieves JW, Bilezikian JP, Lane JM, Einhorn T A, Wang Y, Steinbuch M, Cosman F. Fragility fractures of the hip and femur: incidence and patient characteristics. Osteoporos Int, 2010;21(3):399-408.

2. Ekstrom W, Nemeth G, Samnegard E, Dalen N, Tidermark J (2009). Quality of life after a subtrochanteric fracture: a prospective cohort study on 87 elderly patients. Injury, 2009;40(4):371-376.

3. Russell TA and Taylor JC. Classification of Subtrochanteric fractures. Skeletal trauma 1998;2;18191897.

4. Simmermacher RK, Bosch AM, Van der Werken C. The AO/ASIF-proximal femoral nail (PFN): A new device for the treatment of unstable proximal femoral fractures. Injury. 1999;30:327-32.

5. Schatzker J, Waddell JP. Subtrochanteric fractures of the femur. OCNA 11, 539,1980.

6. Bruce WJ, Rizkallah SM, Kwon YM, Goldberg JA, Walsh WR. A new technique of subtrochanteric shortening in total hip arthroplasty: surgical technique 
and results of 9 cases. J Arthroplasty. 2000

Aug;15(5):617-26.

7. Horn js, Wang yc. The mechanism, traumatic anatomy, and non-operative treatment of intertrochanteric fracture of the femur. Br J Surg. 1964 Aug;51:574-80.

8. Parker MJ, Handoll HH, Bhonsle S, Gillespie WJ.

Condylocephalic nails versus extramesullary implants for extra capsular hip fractures. Cochrane Database System, 2000, 2;CD 000338.

9. Brien WW, Wiss DA, Becker V Jr, Lehman T .

Subtrochanteric femur fractures: a comparison of the Zickel nail, 9.5-degree blade plate, and interlocking nail. J Orthop Trauma 1991;5:458-64.

10. Fasano FJ Jr, Olysav DJ, Stauffer ES. Intramedullary stabilization of neoplastic destructive disease involving the subtrochanteric region of the femur. Orthopedics. 1988 Dec;11(12):1699-704.

11. DiCicco JD, Jenkins M, Ostrum RF. Retrograde nailing for subtrochanteric femur fractures. Am J Orthop (Belle Mead NJ) 2000;29:4-8.

12. What ley JR, Garland DE, Whitecloud T 3rd, Whickstrom J. Subtrochanteric fractures of the femur: treatment with ASIF blade plate fixation. South Med J. 1978 Nov;71(11):1372-5.

13. Bergman GD, Winquist RA, Mayo KA, Hansen ST Jr. Subtrochanteric fracture of the femur. Fixation using the Zickel nail. J Bone Joint Surg Am. 1987 Sep;69(7):103240 . 